\title{
Evolutionary Conservation of the Signaling Proteins Upstream of Cyclic AMP-Dependent Kinase and Protein Kinase $C$ in Gastropod Mollusks
}

\author{
Wayne S. Sossin ${ }^{a}$ Thomas W. Abrams ${ }^{b}$ \\ ${ }^{a}$ Department of Neurology and Neurosurgery, McGill University, Montreal Neurological Institute, \\ Montreal, Que., Canada; ${ }^{b}$ Department of Pharmacology and Program in Neuroscience, University of \\ Maryland School of Medicine, Baltimore, Md., USA
}

\section{Key Words}

Phospholipase C • Adenylate cyclase $\cdot$ Signal transduction • Learning and memory $\cdot$ Serotonin $\cdot$ Synaptic plasticity · Protein kinase A · Aplysia

\begin{abstract}
The protein kinase $C(P K C)$ and the CAMP-dependent kinase (protein kinase $A$; PKA) pathways are known to play important roles in behavioral plasticity and learning in the nervous systems of a wide variety of species across phyla. We briefly review the members of the PKC and PKA family and focus on the evolution of the immediate upstream activators of PKC and PKA i.e., phospholipase C (PLC) and adenylyl cyclase (AC), and their conservation in gastropod mollusks, taking advantage of the recent assembly of the Aplysia californica and Lottia gigantea genomes. The diversity of PLC and AC family members present in mollusks suggests a multitude of possible mechanisms to activate PKA and PKC; we briefly discuss the relevance of these pathways to the known physiological activation of these kinases in Aplysia neurons during plasticity and learning. These multiple mechanisms of activation provide the gastropod nervous system with tremendous flexibility for implementing neuromodulatory responses to both neuronal activity and extracellular signals.
\end{abstract}

Copyright $\odot 2009$ S. Karger AG, Basel

\section{KARGER}

Fax +41613061234

E-Mail karger@karger.ch

www.karger.com
(C) 2009 S. Karger AG, Basel

Accessible online at: www.karger.com/bbe

\section{Introduction}

Within the field of neurobiology, initiation of the action potential, presynaptic release of neurotransmitter and activation of postsynaptic receptors are considered the fundamental processes for neuronal signaling. The assumption has been that the mechanisms for these processes must have appeared early in evolution, as these processes are essential for the functioning of even the most primitive neural circuits. In contrast, the modulation of voltage-gated ion channels, neurotransmitter receptors and synaptic vesicle exocytosis are considered 'higher order' processes, layered on top of these fundamental processes. This perspective derives from the mediating versus modulatory dichotomy [Kupfermann, 1979]. The assumed corollary is that because molecular mechanisms responsible for neuromodulation are likely to have evolved later, neuromodulation is associated with behavioral complexity. Complex modulatory mechanisms should be a distinguishing characteristic of those higher animals that are capable of complex mentation. For example, it was initially suspected that N-methyl-Daspartic acid (NMDA) receptors, which mediate associative integration during hippocampal long-term potentiation, probably were unique to mammals or at least to vertebrates. However, this assumed evolutionary sequence 
that mediating mechanisms preceded modulatory mechanisms does not reflect the biology; a diverse variety of intracellular signal transduction pathways appeared extremely early in evolution. It is noteworthy that well before the appearance of nervous systems, the classic signaling molecules cyclic AMP (cAMP) and calmodulin $(\mathrm{CaM})$ played critical roles in mediating behavior in slime mold and paramecia, respectively. So it should not be surprising that molecular members of signal transduction pathways appeared early and are highly conserved throughout evolution.

Much of neuronal modulation is mediated by protein kinases and their regulation of ion channels, ligand-gated receptors, vesicular release machinery, cytoskeleton, protein translation and gene transcription. The ability of a specific neuron to decrypt multiple neuromodulators and the pattern of their presentation depends on the complexities of the signal transduction pathways. Mollusks have been an attractive system for understanding these pathways due to their large identifiable neurons and the clear links between synaptic physiology and behavior. In the present review, we will focus on the activation of cAMP-dependent protein kinase (protein kinase A; PKA) and protein kinase $\mathrm{C}$ (PKC) in mollusks in general, focusing on Aplysia in particular. The presence of an assembled genome for the opisthobranch Aplysia californica and a draft annotated genome for the prosobranch Lottia gigantea provide an opportunity to examine the molecular players important for the activation of the PKA and PKC pathways in mollusks. Although these pathways are strongly implicated in synaptic plasticity underlying behavioral regulation in both mollusks and vertebrates, the molecular pathways underlying activation of these kinases during learning and modulation of behavioral states are not well understood.

\section{Materials and Methods}

Sequences of transcripts for orthologues to mammalian genes were obtained either from the NCBI site, http://blast.ncbi.nlm. nih.gov/Blast.cgi, or the JGI Genome site, http://genome.jgi-psf. org. Sequences were aligned with Clustal-W, 1,000 replicates were generated with the Phylip program Seqboot and then the Phylip program ProtDist was used with the Jones-Taylor-Thornton model to generate a Distance Matrix. Then the Phylip program Neighbor was used to generate trees from each repetition, the program Consense used to generate the consensus tree and Drawgram used to make the final tree shown. Bootstrap numbers are given for critical nodes and represent the percentage of total trees that gave the tree shown. For more information on the workings of these programs, please see http://evolution.genetics.washington. edu/phylip/phylipweb.html. For trees with low confidence additional blast searches were done with other conserved domains (PH domain, EF-hand or C2 domains for PLCs; C2B domains for adenylyl cyclase (AC) to determine if the closest orthologue for these domains was consistent with orthology.

\section{Contribution of PKC to Neural Plasticity in Aplysia}

PKC was first implicated in the regulation of ion channels in Aplysia, where PKC contributes to changes in action potential shape during prolonged firing of peptidergic neurons associated with release of egg-laying hormone [DeRiemer et al., 1985]. This is due to the insertion of calcium channels [Strong et al., 1987; Zhang et al., 2008], perhaps involving PKC-dependent regulation of the cytoskeleton [Kabir et al., 2001]. PKC also directly modulates a nonselective cation current in these neurons [Magoski et al., 2002; Magoski and Kaczmarek, 2005]. PKC, as well as PKA, is involved in the increase in synaptic strength between the sensory and motor neurons that contributes to sensitization of the defensive withdrawal response of Aplysia. Facilitation of sensory neuron-tomotor neuron synaptic connections is caused by the release of serotonin (5-hydroxy tryptamine, 5-HT) by interneurons [Mackey et al., 1989; Marinesco and Carew, 2002], and 5-HT activates PKC in sensory neurons [reviewed in Sossin, 2007]. Although PKC is required for the modulation of some of the ion channels involved in facilitation of sensory neuron-to-motor neuron synapses [Critz and Byrne, 1992; Sugita et al., 1992], inhibition of PKC does not block 5-HT-mediated facilitation of naïve synapses when 5-HT is applied for $5 \mathrm{~min}$ [Ghirardi et al., 1992; Manseau et al., 2001]; however, PKC is critical for the facilitation by 5 -HT of highly depressed sensory neuron-to-motor neuron synapses [Ghirardi et al., 1992] and PKC might become more important for facilitation with longer applications of 5-HT [Byrne and Kandel, 1996; Hawkins et al., 2006]. PKC is also important for the postsynaptic insertion of $\alpha$-amino-3-hydroxyl-5-methyl-4isoxazole-propionate (AMPA) receptors implicated in facilitation of these synapses [Villareal et al., 2009] and for intermediate and long-term facilitation that occur when 5-HT and activity are paired [Sutton and Carew, 2000; Sutton et al., 2004; Hu et al., 2007]. In operant conditioning of the feeding response of Aplysia [Susswein et al., 1986; Botzer et al., 1998], Byrne and colleagues have identified the neuron B51, which is a member of the feeding system central pattern generator, as one locus of associative modification. During an analog of conditioning, 
Fig. 1. Alignment of the last exon in classical PKCs from a number of organisms showing the differential splicing in mollusks and vertebrates. Shaded residues are conserved in all species. Residues in green are specifically conserved between the nervous system exon in Aplysia, the orthologous exon in Lottia and vertebrate PKC $\beta 1$, but not conserved in the alternative exon. The * signifies conserved phosphorylation sites in PKCs.

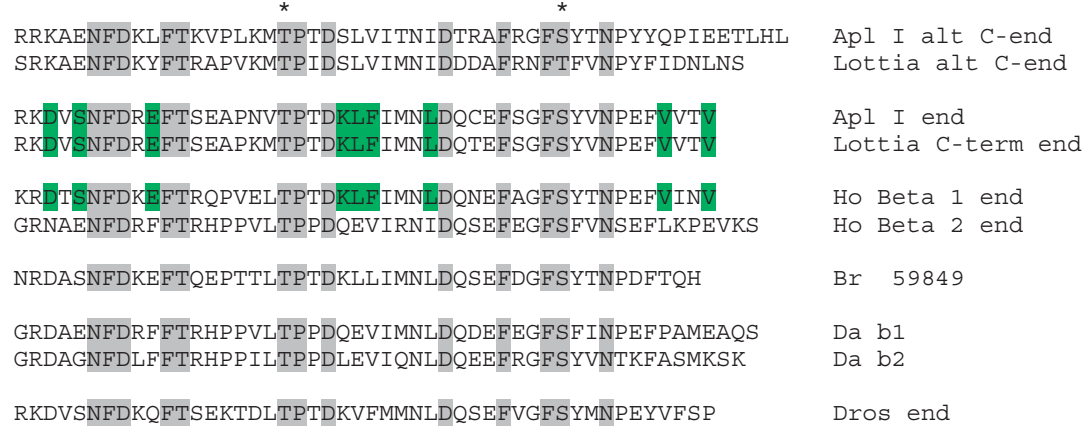

Apl I alt C-end

Lottia alt $\mathrm{C}$-end

Apl I end

Lottia C-term end

Ho Beta 1 end

Ho Beta 2 end

Br $\quad 59849$

$\mathrm{Da}$ b1

Da b2

Dros end

when dopamine is paired with depolarizing plateau potentials in B51, the threshold for initiating plateau potentials and bursts in B51 is reduced [Lorenzetti et al., 2008; Mozzachiodi et al., 2008]. PKC activation is required for this associative change in B51 [Lorenzetti et al., 2008].

\section{PKC Family}

The origins of the family of PKCs and the role of these kinases in plasticity has been recently reviewed [Sossin, 2007] and will be summarized below. There are four ancient PKC families. The classical PKCs contain an internal C2 domain that provides regulation by calcium ions and is represented by PKCs $\alpha, \beta$ and $\gamma$ in vertebrates and PKC Apl I in Aplysia. The novel type I PKC family contains an $\mathrm{N}$-terminal $\mathrm{C} 2$ domain that is not responsive to calcium and is represented by PKC Apl II in Aplysia, and in vertebrates by PKCs $\varepsilon$ and $\eta$. The novel type II family also contains an N-terminal C2 domain, however this C2 domain is not evolutionarily related to the $\mathrm{C} 2$ domain in novel type I kinases, and the two families of novel PKCs diverged before the bilaterian ancestor [Sossin, 2007]. This family is characterized by PKCs $\delta$ and $\Phi$ in vertebrates. There is bioinformatic data for the presence of a PKC $\delta$ in Lottia, and searches of the assembled Aplysia genome shows a fragment of the genome (contig no. 16073) with high homology to the catalytic domain of $\mathrm{PKC} \delta$, although at this point the remainder of the putative PKC Apl IV cannot be identified from the assembled genome. Phorbol esters are pharmacological activators of $\mathrm{PKC}$, which work through binding to the $\mathrm{Cl}$ domains of PKC, mimicking the endogenous activator diacylglycerol (DAG). Experiments that examined immunoprecipitation of phorbol ester-stimulated PKC activity in Aplysia from the nervous system suggest that over $90 \%$ of the phorbol-ester stimulated kinase activity is mediated by PKC Apl I and PKC Apl II [Sossin et al., 1993] and thus, there are probably only low levels of a putative phorbolester-activated PKC Apl IV expressed in the Aplysia nervous system. The final PKC family is the atypical family that includes PKCs $\zeta$ and $\iota$ in vertebrates and PKC Apl III in Aplysia. These kinases are not activated by phorbol esters due to the atypical $\mathrm{Cl}$ domain that gives this isoform its name. In vertebrates, there is an alternative transcript encoding a shortened form of PKC $\zeta$, called PKM $\zeta$, that is important for retention of memory [Hernandez et al., 2003; Pastalkova et al., 2006]; this alternative transcript does not appear to be present in mollusks [Bougie et al., 2009]. It appears to have evolved only in chordates after the duplication of the atypical PKC into PKC $\iota$ and PKC $\zeta$ [Bougie et al., 2009]. Instead, PKC Apl III might be cleaved to form a PKM Apl III with similar activities as the vertebrate PKM $\zeta$ [Bougie et al., 2009; Villareal et al., 2009].

In the initial cloning of PKC Apl I, there was evidence for an alternatively spliced carboxy terminus, similar to the alternative splicing of PKC $\beta 1$ and PKC $\beta 2$ in vertebrates. In this experiment, an RNA protection assay using the carboxy-terminal region of PKC Apl I fully protected most of the nervous system PKC Apl I mRNA, but a smaller fragment was detected mainly outside the nervous system, suggesting alternative splicing [Kruger et al., 1991]. The assembled Aplysia genome shows a putative alternative exon for PKC Apl I and this alternative exon is also found in Lottia, suggesting conservation of this alternative splicing in mollusks (fig. 1). The presence of the alternative exon in the Aplysia and Lottia EST databases confirms its use. The intron/exon structure of classical PKCs is well conserved and the alternative exon 
usage in Apl I is the same exon alternatively spliced in PKC $\beta 1$ and PKC $\beta 2$. It is not clear, however, if this is an ancient alternative splice form or whether splicing evolved independently in mollusks and vertebrates. Although the carboxy-terminal region of the original PKC Apl I shows significantly increased homology to PKC $\beta 1$, compared to PKC $\beta 2$, the new alternative exon does not show any increased homology to PKC $\beta 2$ (fig. 1), and the increased homology to PKC $\beta 1$ could be due to evolutionary pressure to conserve this sequence, as opposed to shared homology.

The atypical PKC Apl III also has alternative splice forms that are enriched in the nervous system of Aplysia [Bougie et al., 2009]. In this case, two alternative exons are included in the hinge domain, which creates a more favorable calpain cleavage site for production of a PKM [Bougie et al., 2009]. These alternative exons could not be identified in the Lottia genome, however, and might be a recent evolutionary event after the separation of Lottia and Aplysia.

\section{Physiological Activation of PKCs in Aplysia}

The requirements for activation of the PKC isoforms have been studied in sensory neurons of Aplysia using live imaging. Translocation of PKC Apl II by 5 -HT in sensory neurons requires both DAG produced by phospholipase $\mathrm{C}$ (PLC) and phosphatidic acid produced by phospholipase D (PLD) [Farah et al., 2008]. PKC Apl I requires both diacylglycerol and calcium ions and in sensory neurons is only translocated by the conjunction of 5-HT and calcium entry through depolarization [Zhao et al., 2006]. In contrast, in Aplysia B51 neurons, PKC Apl I might be activated by depolarization alone [Lorenzetti et al., 2008]. Indeed even in Aplysia sensory neurons calcium influx during activity appears to activate PKC, based on the ability of brief bursts of action potentials to inhibit synaptic depression in a PKC-dependent manner [Gover and Abrams, 2009], although live imaging does not reveal translocation of PKC with this paradigm [Zhao et al., 2006]. It is important to remember that PKC may become activated in a prelocalized signaling complex in the absence of visible translocation. Also, translocation to a specialized microdomain can be missed without specific markers for this microdomain. PKC Apl III does not bind to DAG and is not translocated by phorbol esters or by 5 HT [Bougie et al., 2009]. There are two mechanisms for activation of the kinase, however: increased phosphorylation in a PI-3 kinase-dependent manner and cleavage to form a PKM [Bougie et al., 2009]. Overexpression of PKC Apl III appears to be sufficient to induce cleavage by calpain. Pharmacological data suggest that calpain-mediated PKM formation from PKC Apl III after 5-HT addition is important for the persistence of the 5-HT-initiated increase in the response of the motor neuron to exogenous glutamate [Bougie et al., 2009; Villareal et al., 2009]. There is also evidence for calpain-mediated cleavage of PKC as important for persistent activation of PKC after the pairing of coincident activity and 5-HT [Sutton et al., 2004]. In this case, activation of PKC Apl I in the sensory neuron has been demonstrated to be required for the induction of this plasticity [Zhao et al., 2006], although it is possible that PKC Apl I activation is required for subsequent cleavage of PKC Apl III.

The critical enzyme involved in activation of PKC Apl I and PKC Apl II is PLC, which converts PIP-2 to DAG and inositol triphosphate $\left(\mathrm{IP}_{3}\right)$. It has been argued that 5HT does not activate PLC in sensory neurons due to the lack of the ability of 5-HT to induce a detectable $\mathrm{IP}_{3}$-mediated increase in cytosolic calcium in the sensory neurons [Blumenfeld et al., 1990]; however, inhibitors of PLC block translocation of PKC Apl II in sensory neurons [Farah et al., 2008]. This discrepancy could be due to poor coupling of the $\mathrm{IP}_{3}$ produced by phospholipase $\mathrm{C}$ to calcium release, or to a need for constitutively active PLC for PKC Apl II activation. In the motor neuron, 5-HT-mediated increases in AMPA receptor current require both PLC and $\mathrm{IP}_{3}$ [Li et al., 2005; Fulton et al., 2008], but 5-HT poorly translocates PKC Apl I and PKC Apl II in motor neurons, compared with sensory neurons [Zhao et al., 2006]. One possibility to explain the above is that isoforms of PLC in the sensory and motor neurons are differentially coupled to $\mathrm{IP}_{3}$ receptors and PKC translocation. Below we will review the PLC isoforms present in mollusks based on bioinformatic analysis of the Aplysia and Lottia genomes.

\section{Evolution of PLCs}

PLCs have a number of conserved domains. The most conserved domain is the catalytic region, which can be divided into the $\mathrm{X}$ and $\mathrm{Y}$ domains, which are separated in the primary sequence of most isoforms. We first attempted to find all the $\mathrm{X}$ and $\mathrm{Y}$ catalytic domains for PLCs in Aplysia and Lottia using extensive searches with all known vertebrate PLC isoforms and selected invertebrate $\mathrm{X}$ and $\mathrm{Y}$ domains. We excluded those sequences with highest similarity to the PLC-like family that repre- 
Fig. 2. Results of a Phylip analysis of merged X and Y domains of PLCs from different species. Six different families were identified, shown on the right. For the vertebrates, human (Hom) and Danio (DAN), the accepted name of the PLC is given. For the primitive chordates, Branchiostoma (BRA) and Ciona (CIO), the protein IDs are given from the NCBI entry. For Apis (API) and Capitella (CAP), the protein IDs are given from the NCBI and JGI genome sites, respectively, and for Drosophila (DRO), the accepted gene names are used. For the mollusks the names are blue. For Aplysia (APL) the contig from the NCBI site containing the $\mathrm{X}$ and Y domains is given. For Lottia (LOT) the protein IDs are given from the JGI genome site. The numbers represent the percentage of trees generated by the Phylip protein Neighbour that contained the tree shown. Only selected branches are highlighted to emphasize the division into PLC families. The outgroup (not shown) was yeast (Schizosaccharomyces pombe) PLC.

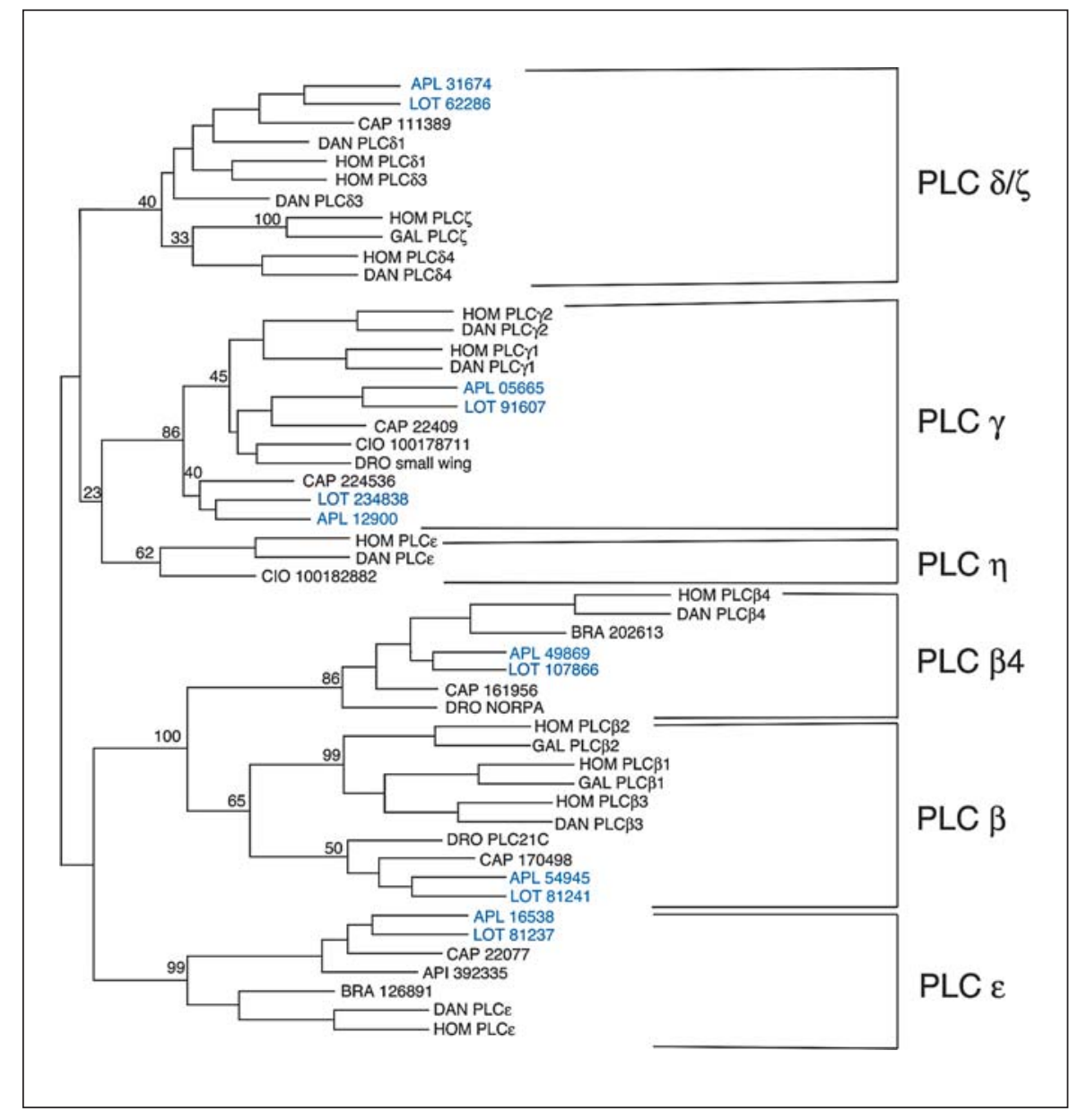

sents natural inhibitors of PLCs with no enzymatic activity. There are at least two of these PLC-like isoforms in mollusks, and one of these was recently cloned [Cummins et al., 2009]. For phylogenetic analysis of the molluscan PLCs, we used catalytic domains from: (i) two vertebrates, human (Homo) and zebrafish (Danio), or, if the human isoform was not present in zebrafish, chicken (Gallus); (ii) one primitive chordate, either Branchiostoma or Ciona; (iii) one arthropod, Drosophila, or, if not present, bee (Apis); and (iv) Capitella, a marine polychaete (Annelida), which might be more closely related to mollusks than insects or deuterostomes. The results of this analysis are shown in figure 2 .

There are six families of PLCs in humans, PLCs $\beta, \gamma$, $\delta, \varepsilon, \eta$ and $\zeta$ [Suh et al., 2008]. There are also multiple genes in many of these families, 4 PLC $\beta s$ (1-4), 2 PLC $\gamma s$ $(1,2), 3$ PLC $\delta s(1,3,4)$ and 2 PLC $\eta s(1,2)$ [Suh et al., 2008]. Although all of these PLCs have the same enzymatic function, they differ in how they are activated (see below). In Aplysia and Lottia, four of these families are present, $\beta, \gamma, \delta$ and $\varepsilon$. We will discuss each family below.

PLC $\beta$ isoforms are activated by the G protein Gq. All invertebrates, including prebilaterians (Hydra) [Koyanagi et al., 1998] contain two PLC $\beta$ isoforms, one orthologous to vertebrate PLC $\beta 4$ and one to the ancestor of PLC $\beta 1-3$ (these three vertebrate isoforms duplicated and diverged recently; PLC $\beta 3$ earlier, and PLC $\beta 1$ and PLC $\beta 2$ more recently; fig. 2). This can be seen in the phylogeny of the catalytic domain (fig. 2), but can be replicated with any of the conserved domains. In particular, the C-terminal extension where Gq binds is easily differentiated in the two isoforms, although both are activated by Gq. The ancient divergence of the two PLC $\beta$ isoforms suggests some fundamental differences in their activation by Gq.

PLC $\gamma$ isoforms are activated by receptor tyrosine kinases (RTKs) and contain sarcoma kinase (Src) homology 2 and 3 (SH2 and $\mathrm{SH} 3$ ) domains to allow for interaction 
with activated RTKs [Suh et al., 2008]. The two members of the vertebrate PLC $\gamma$ family diverged through gene duplication before fishes, as only a single PLC $\gamma$ is present in early chordates such as Ciona and also in flies and nematodes. In Lottia, Aplysia, and Capitella, however, there are two genes encoding PLC $\gamma$. One of these is somewhat more similar to the other invertebrate and vertebrate PLCys, whereas the other is less homologous (fig. 2). Whether these additional PLC $\gamma$ s represent an ancient division in the PLC $\gamma$ family that was lost in other branches or a more recently duplicated PLC $\gamma$ gene is unclear.

PLC $\delta$ isoforms have EF hands and are directly activated by calcium [Suh et al., 2008]. The PLC $\delta$ family has three isoforms in vertebrates that had diverged during gene duplications before fishes. Indeed, in fishes there has been another duplication and most fish have two copies of each PLC $\delta$ isoform [Kim et al., 2008]. There appears to be either one or a recently duplicated PLC $\delta$ in primitive chordates based on analysis of X domains, but these sequences were not complete (the $\mathrm{Y}$ domain was lacking) and were not included in this analysis. Insects apparently lack a PLC $\delta$ encoding gene, but Caenorhabditis elegans has a PLC with an EF hand domain and a pleckstrin homology (PH) domain most similar to PLC $\delta$, although its catalytic domain was quite diverged and did not align with other PLCסs (this C. elegans isoform was not included in the Phylip analysis). Both Capitella and Lottia have isoforms most closely related to PLC $\delta$, although in Lottia the $\mathrm{PH}$ domain at its $\mathrm{N}$-terminus is not present in the annotated genome; in Aplysia there is an orthologous catalytic domain and $\mathrm{C} 2$ domain, although the $\mathrm{PH}$ domain and the EF hand could not be found at this point in the genome.

PLC $\varepsilon$ isoforms have a Ras binding domain and are activated by Ras [Suh et al., 2008]. Additional domains allow for activation by Rho via an insert in the Y domain

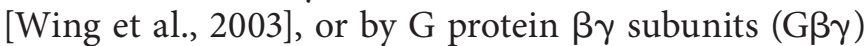
through the PH domain [Wing et al., 2001]. These PLCs also have a guanine exchange factor (GEF) domain that is specific for Rap, and this is important for some physiological effects of PLC $\varepsilon$ [Citro et al., 2007]. There is a single PLC $\varepsilon$ family member in every species examined (fig. 2), and most if not all of the activation domains are conserved. In insects, an additional domain, a glycotransferase domain, has apparently been added to the $5^{\prime}$ end of the protein.

Of the PLC families, two are specific to chordates. The PLC $\zeta$ isoform recently diverged from the PLC $\delta$ family (fig. 2) and this was confirmed with Blast searches of the $\mathrm{PH}$ domain and the $\mathrm{C} 2$ domain of PLC $\zeta$, both of which are more homologous to the $\mathrm{PH}$ and $\mathrm{C} 2$ domain of PLC $\delta$ than to other PLC isoforms. The PLC $\eta$ family is seen in primitive chordates, such as Ciona, but we were unable to find an ortholog in any nonchordate.

\section{Functional Implications of PLC Isoforms for Neuronal Plasticity}

The classical method described for PKC activation is via Gq and PLC $\beta$. Two PLC $\beta$ isoforms exist in mollusks, and it is certainly conceivable that neurotransmitters activate a Gq receptor that in turn activates PLC $\beta$ and PKC. PKC Apl II also requires PLD for translocation [Farah et al., 2008]. Although there are two PLD isoforms in vertebrates, one that is constitutively active and one that is highly regulated, there appears to be a single PLD in all invertebrates, and it is not clear if it is constitutively active or regulated. PLD is activated in a complex manner, but often downstream of small $\mathrm{G}$ proteins of the Rho/Rac family. 5 -HT is known to activate cell division cycle 42 (cdc42) and Rac in Aplysia neurons, but the pathway underlying this is not clear [Udo et al., 2005].

In vertebrates, the orthologue of PKC Apl II, PKC $\varepsilon$ can be activated downstream of exchange protein directly activated by cAMP (EPAC) and PLC $\varepsilon$ [Hucho et al., 2005; Oestreich et al., 2007, 2009]. EPAC is a cAMP-activated GEF for Ras and Rap. A cAMP-activated GEF was recently implicated in activation of PKC Apl I during intermediate-term facilitation, but in this case it appeared to be required for mitogen activated protein kinase (MAP kinase) activation, rather than for activation of PLC [Shobe et al., 2009]. If EPAC were important for PKC activation, this would imply that cAMP increases could lead to PKC Apl II translocation, but this would be inconsistent with some studies of PKC translocation [Sacktor and Schwartz, 1990]. Another mechanism for activation of PLC $\varepsilon$ through Ras in Aplysia is the transactivation of the RTK Ap Trkl by 5-HT [Ormond et al., 2004]. Although Ap Trkl is lacking a site for coupling to PLC $\gamma$, other RTKs in Aplysia probably are coupled to PLC $\gamma$; it will be interesting to determine the importance of RTKs for PKC activation in other paradigms.

The activation of classical PKCs by calcium alone, which is believed to require DAG, might be due either to basal levels of DAG or to calcium-dependent PLC $\delta$ activation. In vertebrate neurons, $\mathrm{PKC} \gamma$ activation by NMDA in hippocampal neurons required PLC $\delta$, whereas activation by glutamate through metabotropic glutamate receptors required PLC $\beta$ [Codazzi et al., 2006]. In Aplysia B51 neu- 
rons, PKC Apl I appears to be activated by plateau potentials in the absence of neurotransmitter activation of a PLC; thus, this activation might be mediated by a PLC $\delta$ isoform [Lorenzetti et al., 2008]. It will be interesting to see if translocation of PKC Apl I by calcium alone, either using ionomycin [Zhao et al., 2006; Lorenzetti et al., 2008] or depolarization, is blocked by PLC inhibitors.

\section{Contribution of CAMP and PKA to Neural Plasticity in Aplysia}

cAMP and PKA have been known to play central roles in behavior in Aplysia for three decades [Brunelli et al., 1976; Weiss et al., 1979]. During sensitization, at Aplysia sensory neuron-to-motor neuron synapses cAMP-dependent phosphorylation contributes to initiation of short-term facilitation [Bernier et al., 1982; Castellucci et al., 1982; Shuster et al., 1985; Goldsmith and Abrams, 1991; Ghirardi et al., 1992; Chang et al., 2000, 2003; Lee et al., 2009], some forms of intermediate-term facilitation [Ghirardi et al., 1995; Sutton and Carew, 2000; Sutton et al., 2001] and long-term facilitation [Schacher et al., 1988; Scholz and Byrne, 1988; Hegde et al., 1997; Martin et al., 1997; Hu et al., 2006; Lee et al., 2006].

During classical conditioning of the defensive withdrawal reflex, the pairing of presynaptic activity and calcium influx in sensory neurons with 5-HT enhanced both synaptic facilitation and cAMP-dependent modulation of potassium currents [Hawkins et al., 1983; Walters and Byrne, 1983; Eliot et al., 1994]. PKA in the sensory neurons contributes to this associative synaptic facilitation and to the associative enhancement of the withdrawal response [Antonov et al., 2003]. Pairing activity or depolarization with 5-HT also enhanced the rise in cAMP in sensory neurons compared with 5-HT alone [Kandel et al., 1983; Ocorr et al., 1985]. Therefore, it was hypothesized that activity and calcium influx and 5-HT might converge at a CaM-sensitive AC [Abrams et al., 1991, 1998] (see below).

In operant conditioning of feeding behavior, $\mathrm{AC}$ also appears to function as an important locus for forming associations. In a cellular analog of operant conditioning in the $\mathrm{B} 51$ neurons, $\mathrm{AC}$ stimulation by dopamine and $\mathrm{G}_{\mathrm{s}}$ is apparently enhanced by $\mathrm{PKC}$, which is activated by calcium influx during plateau potentials; thus AC functions as a site of associative convergence for the dopamine and calcium signals [Lorenzetti et al., 2008].

PKA is also responsible for modulation of ion channels and neuropeptide processing important for initiating re- productive behavior in these marine snails [Kaczmarek and Strumwasser, 1984; Azhderian and Kaczmarek, 1990]. Similarly, food-induced arousal is mediated in part by cAMP and PKA [Weiss et al., 1979; Lloyd et al., 1984; Levitan et al., 1987].

\section{PKA Family}

PKA consists of two subunits, the catalytic subunit and the regulatory subunit. There are three catalytic subunits in vertebrates $(\alpha, \beta$ and $\gamma)$. The three subunits duplicated during the chordate lineage, and primitive chordates have a single PKA catalytic subunit. Interestingly, in some invertebrates there have also been gene duplications. Drosophila has two catalytic subunits and in Aplysia, there is a spermatozoa-specific catalytic subunit [Beushausen and Bayley, 1990]. Although the closest relative to the spermatozoa-specific catalytic subunit is $A p$ lysia PKA, Aplysia PKA is much closer to vertebrate PKAs than to the spermatozoa-specific PKA. This suggests very fast divergence of a recently duplicated protein. Lottia does not appear to have an orthologue of this kinase. There are two splice forms at the C-terminus of Aplysia PKA [Beushausen et al., 1988], but this splicing does not appear to be conserved in Lottia. Drosophila has a PKA$\mathrm{C} 3$, which is related to PKA; in mammals this protein is called X-linked protein kinase or PKA-related protein kinase. There is a PKA-C3 orthologue in Lottia, but a corresponding protein could not be found at this point in the genome of Aplysia.

The regulatory subunit of PKA comes in two forms, named RI and RII. In chordates each of these genes has been duplicated to give four regulatory subunits [Canaves and Taylor, 2002], but in primitive chordates and invertebrates there is a single gene for each type. There are alternative start sites in Aplysia generating two alternative $5^{\prime}$ ends for the R1 protein [Bergold et al., 1992], but this appears to be a recent evolutionary event as the alternative starts are not seen in Lottia.

In Drosophila, the catalytic PKA-C3 is regulated by a separate regulatory protein, named Swiss Cheese [Bettencourt da Cruz et al., 2008]. Swiss Cheese has putative cyclic nucleotide binding sites and a pseudosubstrate and genetically interacts with PKA-C3 in Drosophila [Bettencourt da Cruz et al., 2008]. The Swiss Cheese protein is highly conserved; it is the neuropathy-targeted enolase in vertebrates, and orthologues are present in both the Lottia and Aplysia genomes, although the putative pseudosubstrate sequence is not highly conserved. 


\section{Physiological Activation of PKAs in Aplysia}

As summarized above, activation of PKA is a critical step in synaptic facilitation in Aplysia sensory neurons. Interestingly the two regulatory subunits appear to be specialized for two separate functions of PKA. The RII protein is enriched at synapses and is critical for the activation of PKA during short-term facilitation [Liu et al., 2004]. The RI subunit, present in the cell body, is specifically degraded by the ubiquitin pathway, and this is important for the persistent activation of PKA required to induce long-term facilitation [Hegde et al., 1993; Chain et al., 1999]. Persistent PKA activity is also important for intermediate forms of facilitation and can serve as the memory trace for at least $12 \mathrm{~h}$ after training, but does not appear to be important $24 \mathrm{~h}$ later [Hegde et al., 1993; Chain et al., 1999]. The mechanism of the generation of the persistent PKA memory trace, which requires translation, is not clear, as this PKA must act at the synapse to increase synaptic strength, but the RII subunit that predominates at the synapse is not degraded [Kurosu et al., 2007].

\section{Evolution of ACs}

Enzymes that synthesize cAMP and cyclic GMP (cGMP) have evolved independently on multiple occasions. In prokaryotes there are more than three distinct groups of cyclases [Danchin, 1993; Baker and Kelly, 2004]. One group of these purine nucleotide cyclases, the class III cyclases, resembles the membrane-associated ACs of multicellular animals, in that they have a highly conserved catalytic domain (corresponding to the $\mathrm{C} 2 \mathrm{~A}$ domain of these metazoan transmembrane ACs; see fig. 3). In bacteria, the catalytic site that binds the purine molecule is formed by a pair of catalytic domains from two separate cyclase monomers. When the enzyme is membrane-associated in prokaryotes, the $\mathrm{N}$-terminal region contains a series of transmembrane $\alpha$ helices, whereas the C-terminal region contains the purine-binding catalytic domain [Baker and Kelly, 2004]. The ACs of metazoans evolved through an intragenic duplication, so that in a single protein there are two catalytic domains located within two cytoplasmic regions, C1 and C2 [Tesmer et al., 1997; Cooper, 2003]. It should be noted that these domains represent conserved domains of $\mathrm{AC}$ and have no relationship to the conserved domains of PKC also named $\mathrm{C} 1$ and $\mathrm{C} 2$. There are also two sets of 6 membrane-spanning $\alpha$ helices, with the second set of transmembrane $\alpha$ helices interposed between the $\mathrm{C} 1$ and $\mathrm{C} 2$ cytoplasmic domains. This suggests that the full sequence of a prokaryotic AC has been duplicated. Among the membraneassociated ACs of metazoans, the C1A and C2A catalytic domains are the most conserved sequences. We used these two conserved domains from each of the human membrane-associated AC isoforms to search for ACs in a manner similar to that described earlier for PLC. In this analysis, we did not investigate the soluble, bicarbonateregulated AC of vertebrates, which is a member of a different subgroup of class III cyclases. To assess whether candidate sequences might be authentic ACs, we used the presence of the highly conserved GDCYYC sequence in each $\mathrm{C} 1 \mathrm{~A}$ domain and conserved residues in each $\mathrm{C} 2 \mathrm{~A}$ domain (multiple glycine residues, as well as the specific lysine and aspartate residues that distinguish ACs from guanylyl cyclases; see fig. 3). In a number of instances, we excluded homologous sequences when either the C1A or C2A domain was lacking. Four isoforms of Aplysia AC had already been cloned using degenerate primers [Lin et al., in preparation]. The following section discusses the phylogenetic relationships among the ACs that were identified.

Of the nine mammalian ACs, five can be grouped into two families: AC2, AC4 and AC7, which are closely related, and AC5 and AC6, which are $>90 \%$ identical in their catalytic domains. In contrast, types 1, 3, 8 and 9 AC are each relatively distinct from the other mammalian ACs. Of these two groups and the 4 distinct ACs, all are represented in mollusks, except for AC8. Drosophila has an additional family of ACs (four ACX ACs) that is not conserved in either vertebrates or other invertebrates; the ACX ACs play a specific role in spermatogenesis [Cann et al., 2000]. Most of our understanding of the regulation of ACs comes from studies of mammalian ACs; in addition, several Drosophila ACs and two Aplysia ACs have been expressed and studied biochemically. The membrane-associated mammalian ACs are activated by the $\alpha$ subunit of the $\mathrm{G}_{\mathrm{s}}$ heterotrimeric protein, with the exception of AC8, which has been reported to display minimal Gs stimulation [Baker et al., 1998]. AC types differ in their regulation by $G_{i} \alpha$ and $G \beta \gamma$. A major difference among the AC types is their sensitivity to calcium, and this is of particular importance in the role of ACs in synaptic plasticity (see below). Finally, ACs are regulated by phosphorylation, but, as few of these phosphorylation sites have been identified, it is difficult to know how conserved this regulation will be.

AC1 is activated by $G_{s}$, though in vivo this activation depends on calcium/CaM [Tang et al., 1991; Wayman et 


\begin{tabular}{|c|c|}
\hline HOM_AC1 & DIEKIKTIGSTYMAAVG-RVGINVGPVVAGVIGARRPQYDIWGNTVNVASRMDST \\
\hline HOM_AC2 & GVEKIKTIGSTYMAATG-RVGINHGPVIAGVIGAQKPQYDIWGNTVNVASRMDST \\
\hline HOM_AC3 & ITKIKTIGSTYMAASG-RIGMNKGGVLAGVIGARKPHYDIWGNTVNVASRMEST \\
\hline HOM_AC4 & VVEKIKTIGSTYMAATG-RVGLNHGPVVAGVIGAQKPQYDIWGNTVNVASRMEST \\
\hline HOM_AC5 & LEKIKTIGSTYMAASG-KIGLNIGPVVAGVIGARKPQYDIWGNTVNVASRMDST \\
\hline HOM_AC6 & LEKIKTIGSTYMAASG-KIGLNMGPVVAGVIGARKPQYDIWGNTVNVSSRMDST \\
\hline HOM_AC7 & :VEKIKTIGSTYMAAAG-RVGINHGPVIAGVIGARKPQYDIWGNTVNVASRMEST \\
\hline HOM_AC8 & DIEKIKTIGSTYMAVSG-RIGISHGSVVAGVIGAKKPQYDIWGKTVNLASRMDST \\
\hline HOM_AC9 & SIEKIKTIGATYMAASG-RVGFNHGPLTAGVIGTTKLLYDIWGDTVNIASRMDTT \\
\hline DAN_AC1 & DIEKIKTIGSTYMAAVG-RVGINVGPVVAGVIGARRPQYDIWGNTVNVASRMDST \\
\hline DAN_AC2 Iso A & GVEKIKTIGSTYMAATG-RVGINHGPVKAGVIGAQKPQYDIWGNTVNVASRMDST \\
\hline DAN_AC2 Iso B & GVEKIKTIGSTYMAATG-RVGINHGPVIAGVIGAQKPQYDIWGNTVNVASRMEST \\
\hline DAN_AC3 Iso A & CITKIKTIGSTYMAASG-RIGLNKGAVLAGVIGARKPHFDIWGNTVNVASRMEST \\
\hline DAN_AC3 Iso B & HITKIKTIGSTYMAASG-RIGLNKGSVLAGVIGARKPHFDIWGNTVNVASRMEST \\
\hline DAN_AC6 & QLEKIKTIGSTYMAASG-KIGLNIGPVVAGVIGARKPQYDIWGNTVNVASRMDST \\
\hline DAN_AC7 & GVEKIKTIGSTYMAAAG-RVGINHGPVIAGVIGARKPQYDIWGNTVNVASRMEST \\
\hline DAN_AC8 & DIEKIKTIGSTYMAVSG-RIGMAHGSVVAGVIGAKKPQYDIWGKTVNLASRMDST \\
\hline DAN_688903 & DIEKIKTIGSCYMAASG-RVGISHGPVVAGVIGATKPQYDIWGMTVNLASRMDST \\
\hline DAN_689211 & DIEKIKTIGSCYMAASG-RVGIAHGPVVAGVIGATKPQYDIWGMTVNLASRMDST \\
\hline DRO_RUT & GIDKIKTVGSTYMAVVG-RVGINIGPVVAGVIGARKPQYDIWGNTVNVASRMDST \\
\hline DRO_AC78C-L & SVEKIKTVGATYMAAAG-RVGICSGPLVSGVIGARKPVYDIWGNTVNVASRMDST \\
\hline DRO_AC 76E & GIEKIKTIASTYMCASG-RIGLNHGPVIAGVIGAQKPQYDIWSNTVNVASRMDSC \\
\hline DRO_AC 35C_IsoA & AVEKIKTIGSTFMAASG-RIGMNIGDVTAGVIGTSKLYYDIWGDAVNVASRMDST \\
\hline DRO_ACXB & VVEKIKVVGCTYMAACG-CIGISTGEIMAGVVGASQPHYDIWGNPVNMASRMEST \\
\hline DRO_ACXD & RVEKIKVANWTYMAACG-RIGISHGRAMAGVVGISKPHYDIWGNPVNMASRMDST \\
\hline DRO_ACXE & TVEKIKIVGCTYMAACG-AIGISSGEVMAGIVGASQPHYDIWGNPVNMASRMEST \\
\hline CAP_155468 & CIEKIKTTGSTYMAAAG-RIGINMGPVVAGVIGARKPQYDIWGNAVNVASRMDST \\
\hline CAP_204074 & DVEKIKTIGSCLMAASG-AIGFNYGEVTAGVIGTTKLLYDIWGDTVNVSSRMYST \\
\hline CAP_142277 & SVEKIKTIGSTYMAATG-RIGINHGPAVAGVIGAEKPQYDIWGDTVNVASRMDST \\
\hline CAP_176911 & TITKIKSIGSTCMVASG-RIGINQGSVIAGVIGARKPHYDIWGNSVNVASRMEST \\
\hline CAP_225758 & GVEKIKTIGSTYMVAAG-VQGINHGEVIAGVVGARKPQYDIWGDTVNVASRMESH \\
\hline APL_A & GVEKIKTIGSCYMAATG-RVGINVGPVVAGVIGARKPQYDIWGNTVNVASRMEST \\
\hline APL_B & DVEKIKTIGSTYMAATG-RIGVNHGPVIAGVIGARKPQYDIWGDTVNVASRMDSS \\
\hline APL_C & AVEKIKTVGQTYMCASG-RIGLNIGPVVAGVIGAKKPHYDIWGNTVNVASRMDST \\
\hline APL_D & DVEKIKTISSSFMAAAG-NIGYNFGPVTAGVIGTTKLLYDIWGDTVNIASRMYST \\
\hline LOT_A & AIDKIKTIGSSYMAAIG-KIGVNLGPVVAGVIGARKPQYDIWGNTVNVASRMEST \\
\hline LOT_B & RVEKIKSIGSTYMAATG-RIGINHGPVTAGVVGARKPQYDIWGDTVNVASRMDSS \\
\hline LOT_C & CLEKIKTIGETYMAGSG-RVGINVGPVVAGVIGARKPHYDIWGNTVNVASRMDGT \\
\hline LOT_D & DVEKIKTISSTFMAASG-KIGFNFGEVTAGVIGTTKLLYDIWGDTVNIASRMYST \\
\hline LOT_142752 & CVCKIKTVGPTYMAASG-RIGINHGPIVAGVIGARKPHYDIWGNTVNVASRMEST \\
\hline CEL_504553 & SVEKIKTVGSTYMAAAG-RIGMSVGPLVAGVIGAQKPQYDIWGNTVNLASRMDTH \\
\hline CEL_504486 & KIEKIKTISTTYMVASG-RIGINVGPVVAGVIGSDKPHYDIWGNSVNVASRMDSG \\
\hline CEL_497970 & HIEKIKTIGPAYMAASG-KLGLNIGPVTAGVIGTTKLYYDIWGDTVNIASRMYST \\
\hline
\end{tabular}

Fig. 3. Results of a ClustalW analysis of highly conserved sequences within the catalytic domain of the C2A region of ACs. Residues highlighted in yellow represent amino acids conserved in $90 \%$ or more of the AC isoforms. Residues highlighted in grey represent conserved substitutions. Lysine and aspartate residues indicted in green distinguish adenylyl cyclases from guanylyl cyclases [Baker and Kelly, 2004]. The glycine residue in the Drosophila rutabaga AC highlighted in purple is Gly1026, which is altered to Arg in the rutabaga learning mutant, resulting in complete loss of catalytic activity [Levin et al., 1992]. For human (HOM), standard nomenclature is used; and for corresponding Danio (DAN) isoforms, the same nomenclature is employed. For Drosophila (DRO), gene names are used. For Aplysia (APL) ACs, names are from NCBI and Lin et al. [in preparation]. For Lottia (LOT) isoforms that correspond to Aplysia isoforms, the same nomenclature is used. For C. elegans (CEL), protein IDs are from
NCBI. For Capitella (CAP) and for one Lottia AC, names correspond to protein IDs from the JGI Genome site. For Drosophila, two of the members of the ACX family, ACXA and ACXC, have been omitted from the analysis, as they are extremely similar to ACXB. To facilitate comparison with the genome sites, AC IDs that are somewhat different from those in the databases are listed below. C. elegans: NP_504553; NP_504486, NP_497970. Danio $\mathrm{AC1}=\mathrm{XP}$ _685077; Danio AC2 iso A = XP_692173; Danio AC2 iso $\mathrm{B}=$ NP_001093457; Danio AC3 iso A = XP_700547; Danio AC3 iso $\mathrm{B}=\mathrm{XP}$ 693142; Danio AC6 = XP_001922749; Danio AC7 = XP_001922494; Danio AC8 = NP_001137224; Drosophila ACXD = ACK77593; Lottia A = 141290; Lottia B = 187968/231713; Lottia $\mathrm{C}=135065 ;$ Lottia D = 136240/170789. (For Lottia B and D, on JGI, the C1A and C2A domains were given two separate proteins numbers.) 
al., 1994]. The type I class of AC is highly conserved and a single orthologue is present in Aplysia, Lottia and Drosophila. Three of the invertebrate AC1 orthologues, ACAplA in Aplysia, the orthologous type A AC in Lottia and rutabaga in Drosophila, are unusual among ACs in that they have a particularly long C-terminal domain (the C2 domain is 1,089 amino acids in AC-AplA and 1,351 amino acids in rutabaga, as compared with 316 amino acids in AC1). The functional significance of the longer C2 domains in this group of invertebrate ACs is not known.

ACs 2, 4, and 7 constitute a single class of ACs that are activated by $G$ protein-coupled receptors via $G \beta \gamma$, as well as by $\mathrm{G}_{\mathrm{s}}$ [Tang and Gilman, 1991; Taussig et al., 1994; Cooper, 2003]. These ACs are all calcium-independent. This family of paralogues appears to have diverged during the chordate lineage. Danio has both an AC2 and an AC7. Only mammals have a type 4 AC; no AC4 orthologue was found in either Danio or Gallus. In contrast, the invertebrates appear to have only a single member of this family, but the most homologous ACs, such as AC$\mathrm{AplB}$, are not very closely related to any of the vertebrate AC2-AC4-AC7 group (with the exception of the Dro_76E $\mathrm{AC}$, the groupings of the related invertebrate ACs with this vertebrate AC2/4/7 group occurred in fewer than half of the alternative trees that were generated by the Phylip program Neighbor). It will be interesting to determine if the putative orthologues of the AC2/4/7 family in invertebrates are functionally similar to this vertebrate AC family.

AC3 was originally also considered to be CaM-stimulated, although this stimulation is much weaker than for the calcium/CaM-sensitive ACs [Fagan et al., 1996]; moreover, AC3 is effectively inhibited by CaM kinase II, so that the net effect of calcium is inhibitory [Wei et al., 1996, 1998]. Similar to AC1, the AC3 family is well-conserved, and most organisms examined contain an orthologue of this family. Currently, however, an Aplysia orthologue has not been identified in either the genomic assembly or EST databases, either because of loss of this isoform or an incomplete genome. An AC3 orthologue is expressed in Drosophila olfactory tissues and CNS, and is also inhibited by calcium [Iourgenko and Levin, 2000].

AC5 and AC6 are closely related isoforms that are directly inhibited by micromolar concentrations of calcium [Guillou et al., 1999]. In contrast, most other AC types are inhibited by calcium, but only at concentrations substantially above physiological levels $(>10 \mu \mathrm{M}$ calcium) [Guillou et al., 1999]. AC5 and AC6 represent a recent duplication, as Danio appears to have only a single member of this group, similar to AC6 (although there is a suggestion of a degenerate AC5 homologue in the $D a$ nio genome). Most invertebrates examined have a single member of this family. It is noteworthy that the members of the AC5/6 group are particularly well-conserved across evolution. AC-AplC, the Aplysia orthologue of AC5 and AC6, was also inhibited by micromolar calcium when expressed in heterologous cells [Lin et al., in preparation].

AC8 has been reported to display minimal $G_{s}$ stimulation [Baker et al., 1998]. AC8 binds CaM in the C2 domain, whereas $\mathrm{ACl}$ binds $\mathrm{CaM}$ in the $\mathrm{C} 1$ domain; thus these two ACs appear to have evolved CaM stimulation independently [Wu et al., 1993; Levin and Reed, 1995; Gu and Cooper, 1999]. In Danio, there are three AC8 isoforms, suggesting gene duplication of this isoform in fish. In this phylogenetic analysis, AC8 in chordates appears to have evolved from the same precursor as AC3 (fig. 4); however, pairwise comparisons of the catalytic domains of mammalian ACs suggest that AC8 may be no closer to $\mathrm{AC} 3$ than to other ACs, and therefore the precursor AC to AC8 is not certain.

AC9 has the least resemblance to the other mammalian membrane-associated AC isoform, and $80 \%$ of the trees generated had AC9 in a separate branch from all other ACs (fig. 4). AC9 has distinct regulatory properties, as it has been found that its activation is enhanced by both CaM kinase II and PKC [Cumbay and Watts, 2005]. The PKC regulation may be complex as inhibition by PKC has also been reported [Cumbay and Watts, 2004]. Consistent with stimulation by these kinases, the CaM-activated phosphatase calcineurin inhibits AC9 [Paterson et al., 1995; Antoni et al., 1998]. There is a clearly related AC9 orthologue in each invertebrate species examined, suggesting strong conservation of a specific function for this isoform. It should be noted that the Danio genome does not appear to have a complete AC9 orthologue, although there are predicted transcripts that code for truncated AC9-like proteins; these transcripts have highly conserved AC9 sequences, corresponding to either the $\mathrm{C} 1 \mathrm{~A}$ or the $\mathrm{C} 2 \mathrm{~A}$ domain, but not both. It is not possible to determine from the NCBI database whether these represent incomplete assemblies or whether a functional type $9 \mathrm{AC}$ has been lost in Danio. Although Danio may not express an AC9, a type 9 AC isoform is present in at least some lower vertebrates; Takifugu (Fugu) has two AC9 orthologues and Xenopus laevis has one. 
Fig. 4. Results of a Phylip analysis of the C2A domains of AC from different species. For the vertebrates, human (Hom) and Danio (DAN), the accepted name of the $\mathrm{AC}$ is given. For $C$. elegans (CEL), the gene numbers from the NCBI genome site are used and for Drosophila (DRO), the accepted gene names are used, for Capitella (CAP) the protein IDs are given from the JGI genome site. For the mollusks the names are blue. For Aplysia (APL) the name from Lin et al. [in preparation] is used. For Lottia (LOT), the same designations are used as for Aplysia when the ACs correspond to the Aplysia ACs; for the fifth AC from Lottia, the protein ID from the JGI genome site is used. Further explanation of the protein IDs is included in the legend for figure 3 . The numbers represent the percentage of trees generated by the Phylip protein Neighbour that contained the tree shown. Only selected branches are highlighted to emphasize the division into AC families. Dictyostelium ACA (not shown) served as the outgroup for this analysis.

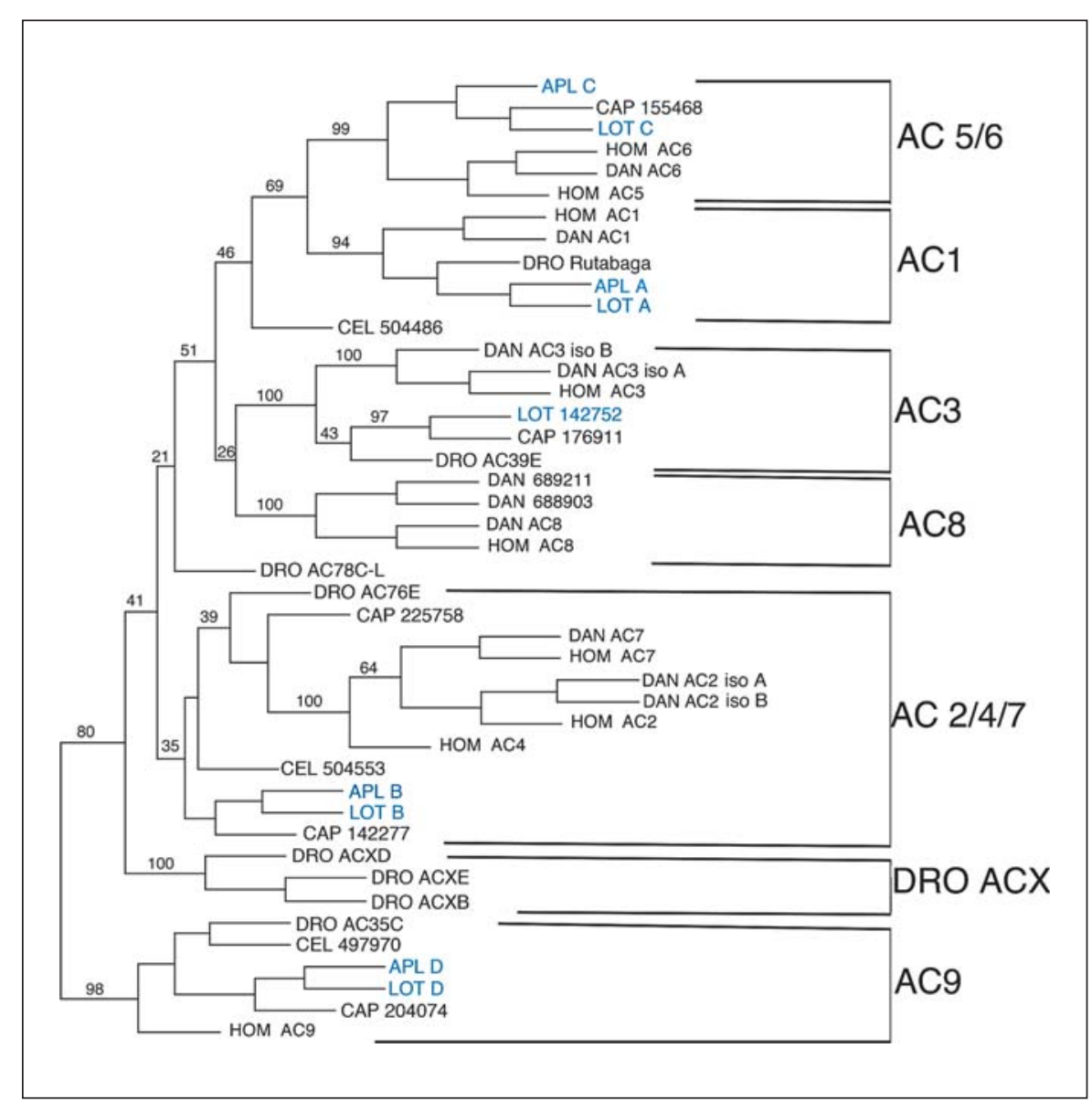

Functional Implications of AC Isoforms for Neuronal Plasticity

Although cAMP and PKA have been repeatedly implicated in neuromodulation during behavioral plasticity and learning in Aplysia, in most instances, nothing is known about the characteristics of the AC enzymes that mediate these modulatory effects. In the CNS of Aplysia, four classes of ACs are expressed: AC-AplA, which is related to $\mathrm{AC} 1, \mathrm{AC}-\mathrm{AplB}$, which resembles the $\mathrm{AC} 2 / 4 / 7$ group; AC-AplC, which is a member of the $\mathrm{AC} 5 / 6$ group; and AC-AplD, which resembles AC9.

In the context of associative learning, $\mathrm{AC}$ has twice been suggested to play a central role as a molecular detector of stimulus pairing. In the first instance, the property of convergent activation by $\mathrm{G}_{\mathrm{s}}$ and calcium/CaM of the AC1 family (and AC8 family in vertebrates) was hypothesized to be important for associative integration. This associative convergence model was developed in studies of activity-dependent facilitation during classical condi- tioning of the defensive withdrawal reflex of Aplysia. As discussed above, in this conditioning paradigm, calcium influx during sensory-neuron activity and 5-HT apparently converge in activating CaM-sensitive $\mathrm{AC}$ in these sensory neurons [Kandel et al., 1983; Ocorr et al., 1985; Abrams et al., 1991]. CaM-sensitive AC is also important in associative learning in Drosophila and mice. In Drosophila, a mutant called rutabaga was found to have a point mutation in an $\mathrm{AC} 1$ orthologue; this mutation entirely eliminated the activity of the rutabaga AC and was deficient in associative conditioning [Dudai and Zvi, 1984; Livingstone et al., 1984; Levin et al., 1992; McGuire et al., 2003]. In mammals, Storm and colleagues found that double-knockout mice, lacking both $\mathrm{AC} 1$ and $\mathrm{AC} 8$, have deficits in some forms of associative learning [Wong et al., 1999]. The similarity of AC-AplA to rutabaga and $\mathrm{AC1}$, suggested that this isoform is the CaM-sensitive AC in Aplysia CNS. Lin et al. [in preparation] have demonstrated that AC-AplA is indeed stimulated by calcium, via CaM. Moreover this same isoform of $\mathrm{AC}$ is expressed 
in the presynaptic sensory neurons, where it is activated by 5 -HT. Thus, AC-AplA has the correct expression pattern and the appropriate properties to mediate associative integration of paired calcium and 5-HT stimuli during conditioning of the defensive withdrawal reflex. It should be noted that pre- and postsynaptic changes involving calcium and PKC have also been implicated in associative facilitation at these sensory neuron-to-motor neuron synapses [Murphy and Glanzman, 1996, 1997, 1999; Villareal et al., 2009; Shobe et al., 2009], and thus AC-AplA might not be the only locus for association in this system.

In operant conditioning, another form of associative memory, an AC also appears to serve as an important locus for forming associations. As discussed above, the association is proposed to be mediated by convergent activation of an $\mathrm{AC}$ by $\mathrm{G}_{\mathrm{s}}$ (activated by dopamine) and $\mathrm{PKC}$ Apl I (activated by calcium influx during plateau potentials) [Lorenzetti et al., 2008]. AC-AplB resembles the members of the AC2/4/7 family, which are stimulated by PKC [Ishikawa, 1998; Cooper, 2003]. The region of AC2 that is directly regulated by PKC is not known [Levin and Reed, 1995], however, so we do not know if it is conserved in AC-AplB. It is also possible that PKC might regulate other AC isoforms.

\section{Conclusions}

PKA and PKC are important for many aspects of neuronal plasticity in mollusks. The ability to activate these kinases through many distinct pathways due to the multiplicity of upstream enzymes (ACs and PLCs) that produce their second messengers allows these kinases to respond both to multiple types of signals and to be sensitive to the conjunction of signals required for associative plasticity. Interestingly, these kinases can both cooperate [Lorenzetti et al., 2008] or antagonize [Sugita et al., 1997; Farah et al., 2009] each other, and the difference probably depends both on the pattern of stimulation and the presence or absence of specific upstream pathways. The richness of the plasticity paradigms and the molecular and biochemical information in this system provides the opportunity for in-depth examination of how different neuromodulators and activity combine to activate synaptic plasticity.

\section{Acknowledgement}

This work was supported by CIHR Grant MOP 12046 to W.S.S. and National Institute of Mental Health Grant MH-55880 to T.W.A. W.S.S. is a James McGill Scholar and an FRSQ Chercheur National.

\section{References}

- Abrams TW, Karl KA, Kandel ER (1991) Biochemical studies of stimulus convergence during classical conditioning in Aplysia: dual regulation of adenylate cyclase by $\mathrm{Ca} 2+1$ calmodulin and transmitter. J Neurosci 11: 2655-2665.

-Abrams TW, Yovell Y, Onyike CU, Cohen JE, Jarrard HE (1998) Analysis of sequence-dependent interactions between transient calcium and transmitter stimuli in activating adenylyl cyclase in Aplysia: possible contribution to CS-US sequence requirement during conditioning. Learn Mem 4:496-509.

-Antoni FA, Palkovits M, Simpson J, Smith SM, Leitch AL, Rosie R, Fink G, Paterson JM (1998) Ca2+/calcineurin-inhibited adenylyl cyclase, highly abundant in forebrain regions, is important for learning and memory. J Neurosci 18:9650-9661.

-Antonov I, Antonova I, Kandel ER, Hawkins RD (2003) Activity-dependent presynaptic facilitation and Hebbian LTP are both required and interact during classical conditioning in Aplysia. Neuron 37:135-147.

-Azhderian EM, Kaczmarek LK (1990) Cyclic AMP regulates processing of neuropeptide precursor in bag cell neurons of Aplysia. J Mol Neurosci 2:61-70.
Baker DA, Kelly JM (2004) Structure, function and evolution of microbial adenylyl and guanylyl cyclases. Mol Microbiol 52:1229-1242.

- Baker LP, Nielsen MD, Impey S, Metcalf MA, Poser SW, Chan G, Obrietan K, Hamblin MW, Storm DR (1998) Stimulation of type 1 and type $8 \mathrm{Ca} 2+/$ calmodulin-sensitive adenylyl cyclases by the Gs-coupled 5-hydroxytryptamine subtype 5-HT7a receptor. J Biol Chem 273:17469-17476.

-Bergold PJ, Beushausen SA, Sacktor TC, Cheley S, Bayley H, Schwartz JH (1992) A regulatory subunit of the cAMP-dependent protein kinase down-regulated in Aplysia sensory neurons during long-term sensitization. Neuron 8:387-397.

Bernier L, Castellucci VF, Kandel ER, Schwartz JH (1982) Facilitatory transmitter causes a selective and prolonged increase in adenosine $3^{\prime}: 5^{\prime}$-monophosphate in sensory neurons mediating the gill and siphon withdrawal reflex in Aplysia. J Neurosci 2:1682-1691.

Bettencourt da Cruz A, Wentzell J, Kretzschmar D (2008) Swiss cheese, a protein involved in progressive neurodegeneration, acts as a noncanonical regulatory subunit for PKAc3. J Neurosci 28:10885-10892.
Beushausen S, Bergold P, Sturner S, Elste A, Roytenberg V, Schwartz JH, Bayley H (1988) Two catalytic subunits of cAMP-dependent protein kinase generated by alternative RNA splicing are expressed in Aplysia neurons. Neuron 1:853-864.

-Beushausen S, Bayley H (1990) A relative of the catalytic subunit of cyclic AMP-dependent protein kinase in Aplysia spermatozoa. Mol Cell Biol 10:6775-6780.

Blumenfeld H, Spira ME, Kandel ER, Siegelbaum SA (1990) Facilitatory and inhibitory transmitters modulate calcium influx during action potentials in Aplysia sensory neurons. Neuron 5:487-499.

- Botzer D, Markovich S, Susswein AJ (1998) Multiple memory processes following training that a food is inedible in Aplysia. Learn Mem 5:204-219.

Bougie J, Lim T, Farah C, Manjunath V, Nagakura I, Ferraro G, Sossin WS (2009) The atypical protein kinase C in Aplysia can form a PKM by cleavage. J Neurochem 109:11291143.

Brunelli M, Castellucci V, Kandel ER (1976) Synaptic facilitation and behavioral sensitization in Aplysia: possible role of serotonin and cyclic AMP. Science 194:1178-1181. 
Byrne JH, Kandel ER (1996) Presynaptic facilitation revisited: state and time dependence. J Neurosci 16:425-435.

- Canaves JM, Taylor SS (2002) Classification and phylogenetic analysis of the cAMP-dependent protein kinase regulatory subunit family. J Mol Evol 54:17-29.

-Cann MJ, Chung E, Levin LR (2000) A new family of adenylyl cyclase genes in the male germline of Drosophila melanogaster. Dev Genes Evol 210:200-206.

-Castellucci VF, Nairn A, Greengard P, Schwartz JH, Kandel ER (1982) Inhibitor of adenosine 3':5'-monophosphate-dependent protein kinase blocks presynaptic facilitation in Aplysia. J Neurosci 2:1673-1681.

-Chain DG, Casadio A, Schacher S, Hegde AN, Valbrun M, Yamamoto N, Goldberg AL, Bartsch D, Kandel ER, Schwartz JH (1999) Mechanisms for generating the autonomous cAMP-dependent protein kinase required for long-term facilitation in Aplysia. Neuron 22:147-156.

-Chang DJ, Li XC, Lee YS, Kim HK, Kim US, Cho NJ, Lo X, Weiss KR, Kandel ER, Kaang BK (2000) Activation of a heterologously expressed octopamine receptor coupled only to adenylyl cyclase produces all the features of presynaptic facilitation in Aplysia sensory neurons. Proc Natl Acad Sci USA 97:18291834.

Chang DJ, Lim CS, Lee JA, Kaang BK (2003) Synaptic facilitation by ectopic octopamine and 5-HT receptors in Aplysia. Brain Res Bull 60: 73-79.

-Citro S, Malik S, Oestreich EA, Radeff-Huang J, Kelley GG, Smrcka AV, Brown JH (2007) Phospholipase $\mathrm{C}$ epsilon is a nexus for rho and rap-mediated $G$ protein-coupled receptor-induced astrocyte proliferation. Proc Natl Acad Sci USA 104:15543-15548.

-Codazzi F, Di Cesare A, Chiulli N, Albanese A, Meyer T, Zacchetti D, Grohovaz F (2006) Synergistic control of protein kinase $\mathrm{C}$ gamma activity by ionotropic and metabotropic glutamate receptor inputs in hippocampal neurons. J Neurosci 26:3404-3411.

-Cooper DM (2003) Regulation and organization of adenylyl cyclases and cAMP. Biochem J 375:517-529.

-Critz SD, Byrne JH (1992) Modulation of IK, Ca by phorbol ester-mediated activation of PKC in pleural sensory neurons of Aplysia. J Neurophysiol 68:1079-1086.

-Cumbay MG, Watts VJ (2004) Novel regulatory properties of human type 9 adenylate cyclase. J Pharmacol Exp Ther 310:108-115.

-Cumbay MG, Watts VJ (2005) Galphaq potentiation of adenylate cyclase type 9 activity through a $\mathrm{Ca} 2+/$ calmodulin-dependent pathway. Biochem Pharmacol 69:12471256.

-Cummins SF, Leblanc L, Degnan BM, Nagle GT (2009) Molecular identification of candidate chemoreceptor genes and signal transduction components in the sensory epithelium of Aplysia. J Exp Biol 212:2037-2044.
Danchin A (1993) Phylogeny of adenylyl cyclases. Adv Second Messenger Phosphoprotein Res 27:109-162.

DeRiemer SA, Strong JA, Albert KA, Greengard P, Kaczmarek LK (1985) Enhancement of calcium current in Aplysia neurones by phorbol ester and protein kinase C. Nature 313:313316.

Dudai Y, Zvi S (1984) Adenylate cyclase in the Drosophila memory mutant rutabaga displays an altered $\mathrm{Ca} 2+$ sensitivity. Neurosci Lett 47:119-124.

Eliot LS, Hawkins RD, Kandel ER, Schacher S (1994) Pairing-specific, activity-dependent presynaptic facilitation at Aplysia sensorymotor neuron synapses in isolated cell culture. J Neurosci 14:368-383.

Fagan KA, Mahey R, Cooper DM (1996) Functional co-localization of transfected $\mathrm{Ca}(2+)$ stimulable adenylyl cyclases with capacitative $\mathrm{Ca} 2+$ entry sites. J Biol Chem 271: 12438-12444.

-Farah C, Weatherill D, Sossin WS (2009) PKC translocation differentiates spaced and massed training in Aplysia. J Neurosci 29: 10281-10286.

Farah CA, Nagakura I, Weatherill D, Fan X, Sossin WS (2008) Physiological role for phosphatidic acid in the translocation of the novel protein kinase C Apl II in Aplysia neurons. Mol Cell Biol 28:4719-4733.

Fulton D, Condro MC, Pearce K, Glanzman DL (2008) The potential role of postsynaptic phospholipase $\mathrm{C}$ activity in synaptic facilitation and behavioral sensitization in Aplysia. J Neurophysiol 100:108-116.

Ghirardi M, Braha O, Hochner B, Montarolo PG, Kandel ER, Dale N (1992) Roles of PKA and PKCin facilitation of evoked and spontaneous transmitter release at depressed and nondepressed synapses in Aplysia sensory neurons. Neuron 9:479-489.

- Ghirardi M, Montarolo PG, Kandel ER (1995) A novel intermediate stage in the transition between short- and long-term facilitation in the sensory to motor neuron synapse of $A p$ lysia. Neuron 14:413-420.

Goldsmith BA, Abrams TW (1991) Reversal of synaptic depression by serotonin at Aplysia sensory neuron synapses involves activation of adenylyl cyclase. Proc Natl Acad Sci USA 88:9021-9025.

Gover TD, Abrams TW (2009) Insights into a molecular switch that gates sensory neuron synapses during habituation in Aplysia. Neurobiol Learn Mem 92:155-165.

Gu C, Cooper DM (1999) Calmodulin-binding sites on adenylyl cyclase type VIII. J Biol Chem 274:8012-8021.

Guillou JL, Nakata H, Cooper DM (1999) Inhibition by calcium of mammalian adenylyl cyclases. J Biol Chem 274:35539-35545.

Hawkins RD, Abrams TW, Carew TJ, Kandel ER (1983) A cellular mechanism of classical conditioning in Aplysia: Activity-dependent amplification of presynaptic facilitation. Science 219:400-405.
Hawkins RD, Kandel ER, Bailey CH (2006) Molecular mechanisms of memory storage in Aplysia. Biol Bull 210:174-191.

- Hegde AN, Goldberg AL, Schwartz JH (1993) Regulatory subunits of cAMP-dependent protein kinases are degraded after conjugation to ubiquitin: a molecular mechanism underlying long-term synaptic plasticity. Proc Natl Acad Sci USA 90:7436-7440.

-Hegde AN, Inokuchi K, Pei W, Casadio A, Ghirardi M, Chain DG, Martin KC, Kandel ER, Schwartz JH (1997) Ubiquitin C-terminal hydrolase is an immediate-early gene essential for long-term facilitation in Aplysia. Cell 89:115-126.

Hernandez AI, Blace N, Crary JF, Serrano PA, Leitges M, Libien JM, Weinstein G, Tcherapanov A, Sacktor TC (2003) Protein kinase $M$ zeta synthesis from a brain mRNA encoding an independent protein kinase $\mathrm{C}$ zeta catalytic domain. Implications for the molecular mechanism of memory. J Biol Chem 278:40305-40316.

Hu JY, Chen Y, Schacher S (2007) Protein kinase $\mathrm{C}$ regulates local synthesis and secretion of a neuropeptide required for activity-dependent long-term synaptic plasticity. J Neurosci 27:8927-8939.

Hu JY, Wu F, Schacher S (2006) Two signaling pathways regulate the expression and secretion of a neuropeptide required for longterm facilitation in Aplysia. J Neurosci 26: 1026-1035.

Hucho TB, Dina OA, Levine JD (2005) Epac mediates a cAMP-to-PKC signaling in inflammatory pain: an isolectin $\mathrm{b} 4(+)$ neuron-specific mechanism. J Neurosci 25:6119-6126.

Iourgenko V, Levin LR (2000) A calcium-inhibited Drosophila adenylyl cyclase. Biochim Biophys Acta 1495:125-139.

Ishikawa Y (1998) Regulation of cAMP signaling by phosphorylation. Adv Second Messenger Phosphoprotein Res 32:99-120.

- Kabir N, Schaefer AW, Nakhost A, Sossin WS, Forscher P (2001) Protein kinase C activation promotes microtubule advance in neuronal growth cones by increasing average microtubule growth lifetimes. J Cell Biol 152: 1033-1044.

Kaczmarek LK, Strumwasser F (1984) A voltageclamp analysis of currents underlying cyclic AMP-induced membrane modulation in isolated peptidergic neurons of Aplysia. J Neurophysiol 52:340-349.

Kandel ER, Abrams T, Bernier L, Carew TJ, Hawkins RD, Schwartz JH (1983) Classical conditioning and sensitization share aspects of the same molecular cascade in Aplysia. Cold Spring Harb Symp Quant Biol 48 Pt 2: 821-830.

Kim MS, Seo JS, Ahn SJ, Kim NY, Je JE, Sung JH, Lee HH, Chung JK (2008) Duplication of phospholipase C-delta gene family in fish genomes. Genomics 92:366-371. 
-Koyanagi M, Ono K, Suga H, Iwabe N, Miyata T (1998) Phospholipase C cDNAs from sponge and hydra: antiquity of genes involved in the inositol phospholipid signaling pathway. FEBS Lett 439:66-70.

-Kruger KE, Sossin WS, Sacktor TC, Bergold PJ, Beushausen S, Schwartz JH (1991) Cloning and characterization of $\mathrm{Ca}(2+)$-dependent and $\mathrm{Ca}(2+)$-independent $\mathrm{PKCs}$ expressed in Aplysia sensory cells. J Neurosci 11:23032313.

Kupfermann I (1979) Modulatory actions of neurotransmitters. Ann Rev Neurosci 2:447465.

Kurosu T, Hernandez AI, SchwartzJH (2007) Serotonin induces selective cleavage of the PKA RI subunit but not RII subunit in Aplysia neurons. Biochem Biophys Res Commun 359:563-567.

Lee JA, Lee SH, Lee C, Chang DJ, Lee Y, Kim H, Cheang YH, Ko HG, Lee YS, Jun H, Bartsch D, Kandel ER, Kaang BK (2006) PKA-activated ApAF-ApC/EBP heterodimer is a key downstream effector of ApCREB and is necessary and sufficient for the consolidation of long-term facilitation. J Cell Biol 174:827838.

Lee YS, Choi SL, Lee SH, Kim H, Park H, Lee N, Chae YS, Jang DJ, Kandel ER, Kaang BK (2009) Identification of a serotonin receptor coupled to adenylyl cyclase involved in learning-related heterosynaptic facilitation in $\mathrm{Ap}$ lysia. Proc Natl Acad Sci USA 106:1463414639.

- Levin LR, Han PL, Hwang PM, Feinstein PG, Davis RL, Reed RR (1992) The Drosophila learning and memory gene rutabaga encodes a Ca2+/calmodulin-responsive adenylyl cyclase. Cell 68:479-489.

- Levin LR, Reed RR (1995) Identification of functional domains of adenylyl cyclase using in vivo chimeras. J Biol Chem 270:7573-7579.

- Levitan ES, Kramer RH, Levitan IB (1987) Augmentation of bursting pacemaker activity by egg-laying hormone in Aplysia neuron R15 is mediated by a cyclic AMP-dependent increase in $\mathrm{Ca} 2+$ and $\mathrm{K}+$ currents. Proc Natl Acad Sci USA 84:6307-6311.

Li Q, Roberts AC, Glanzman DL (2005) Synaptic facilitation and behavioral dishabituation in Aplysia: dependence on release of $\mathrm{Ca} 2+$ from postsynaptic intracellular stores, postsynaptic exocytosis, and modulation of postsynaptic AMPA receptor efficacy. J Neurosci 25 5623-5637.

Lin AH, Cohen JE, Qin W, Niu K, Cheng, Abrams TW (in prep) Serotonin-dependent plasticity mediated by calmodulin-dependent adenylyl cyclase in Aplysia sensory neurons.

Liu J, Hu JY, Schacher S, Schwartz JH (2004) The two regulatory subunits of Aplysia cAMPdependent protein kinase mediate distinct functions in producing synaptic plasticity. J Neurosci 24:2465-2474.
Livingstone MS, Sziber PP, Quinn WG (1984) Loss of calcium/calmodulin responsiveness in adenylate cyclase of rutabaga, a Drosophila learning mutant. Cell 37:205-215.

Lloyd PE, Kupfermann I, Weiss KR (1984) Evidence for parallel actions of a molluscan neuropeptide and serotonin in mediating arousal in Aplysia. Proc Natl Acad Sci USA 81:2934-2937.

Lorenzetti FD, Baxter DA, Byrne JH (2008) Molecular mechanisms underlying a cellular analog of operant reward learning. Neuron 59:815-828.

- Mackey SL, Kandel ER, Hawkins RD (1989) Identified serotonergic neurons lcbl and rcbl in the cerebral ganglia of Aplysia produce presynaptic facilitation of siphon sensory neurons. J Neurosci 9:4227-4235.

-Magoski NS, Wilson GF, Kaczmarek LK (2002) Protein kinase modulation of a neuronal cation channel requires protein-protein interactions mediated by an Src homology 3 domain. J Neurosci 22:1-9.

Magoski NS, Kaczmarek LK (2005) Association/ dissociation of a channel-kinase complex underlies state-dependent modulation. Neurosci 25:8037-8047.

Manseau F, Fan X, Hueftlein T, Sossin W, Castellucci VF (2001) $\mathrm{Ca}^{2+}$-independent protein kinase C Apl II mediates the serotonin-induced facilitation at depressed Aplysia sensorimotor synapses. J Neurosci 21:12471256.

- Marinesco S, Carew TJ (2002) Serotonin release evoked by tail nerve stimulation in the CNS of Aplysia: characterization and relationship to heterosynaptic plasticity. J Neurosci 22: 2299-2312.

-Martin KC, Casadio A, Zhu H, Yaping E, Rose JC, Chen M, Bailey CH, Kandel ER (1997) Synapse-specific, long-term facilitation of Aplysia sensory to motor synapses: a function for local protein synthesis in memory storage. Cell 91:927-938.

- McGuire SE, Le PT, Osborn AJ, Matsumoto K, Davis RL (2003) Spatiotemporal rescue of memory dysfunction in Drosophila. Science 302:1765-1768.

Mozzachiodi R, Lorenzetti FD, Baxter DA, Byrne JH (2008) Changes in neuronal excitability serve as a mechanism of long-term memory for operant conditioning. Nat Neurosci 11:1146-1148.

-Murphy GG, Glanzman DL (1996) Enhancement of sensorimotor connections by conditioning-related stimulation in Aplysia depends upon postsynaptic $\mathrm{Ca} 2+$. Proc Natl Acad Sci USA 93:9931-9936.

- Murphy GG, Glanzman DL (1997) Mediation of classical conditioning in Aplysia californica by long-term potentiation of sensorimotor synapses. Science 278:467-471.

Murphy GG, Glanzman DL (1999) Cellular analog of differential classical conditioning in Aplysia: disruption by the NMDA receptor antagonist dl-2-amino-5-phosphonovalerate. J Neurosci 19:10595-10602.
Ocorr KA, Walters ET, Byrne JH (1985) Associative conditioning analog selectively increases cAMP levels of tail sensory neurons in Aplysia. Proc Natl Acad Sci USA 82:25482552.

Oestreich EA, Wang H, Malik S, Kaproth-Joslin KA, Blaxall BC, Kelley GG, Dirksen RT, Smrcka AV (2007) Epac-mediated activation of phospholipase $\mathrm{C}$ (epsilon) plays a critical role in beta-adrenergic receptor-dependent enhancement of $\mathrm{Ca} 2+$ mobilization in cardiac myocytes. J Biol Chem 282:5488-5495.

-Oestreich EA, Malik S, Goonasekera SA, Blaxall BC, Kelley GG, Dirksen RT, Smrcka AV (2009) Epac and phospholipase C epsilon regulate $\mathrm{Ca} 2+$ release in the heart by activation of protein kinase $\mathrm{C}$ epsilon and calciumcalmodulin kinase II. J Biol Chem 284:15141522.

Ormond J, Hislop J, Zhao Y, Webb N, Vaillaincourt F, Dyer JR, Ferraro G, Barker P, Martin KC, Sossin WS (2004) Aptrkl, a Trk-like receptor, mediates serotonin-dependent ERK activation and long-term facilitation in $A p$ lysia sensory neurons. Neuron 44:715-728.

- Pastalkova E, Serrano P, Pinkhasova D, Wallace E, Fenton AA, Sacktor TC (2006) Storage of spatial information by the maintenance mechanism of LTP. Science 313:1141-1144.

Paterson JM, Smith SM, Harmar AJ, Antoni FA (1995) Control of a novel adenylyl cyclase by calcineurin. Biochem Biophys Res Commun 214:1000-1008.

-Sacktor TC, Schwartz JH (1990) Sensitizing stimuli cause translocation of protein kinase C in Aplysia sensory neurons. Proc Natl Acad Sci USA 87:2036-2039.

- Schacher S, Castellucci VF, Kandel ER (1988) cAMP evokes long-term facilitation in Aplysia sensory neurons that requires new protein synthesis. Science 240:1667-1669.

- Scholz KP, Byrne JH (1988) Intracellular injection of cAMP induces a long-term reduction of neuronal K+ currents. Science 240:16641666.

Shobe JL, Zhao Y, Stough S, Ye X, Hsuan V, Martin KC, Carew TJ (2009) Temporal phases of activity-dependent plasticity and memory are mediated by compartmentalized routing of MAPK signaling in Aplysia sensory neurons. Neuron 61:113-125.

- Shuster MJ, Camardo JS, Siegelbaum SA, Kandel ER (1985) Cyclic AMP-dependent protein kinase closes the serotonin-sensitive $\mathrm{K}+$ channels of Aplysia sensory neurons in cellfree membrane patches. Nature 313:392395.

Sossin WS, Diaz AR, Schwartz JH (1993) Characterization of two isoforms of protein kinase $\mathrm{C}$ in the nervous system of Aplysia californica. J Biol Chem 268:5763-5768.

- Sossin WS (2007) Isoform specificity of protein kinase Cs in synaptic plasticity. Learn Mem 14:236-246. 
-Strong JA, Fox AP, Tsien RW, Kaczmarek LK (1987) Stimulation of protein kinase C recruits covert calcium channels in Aplysia bag cell neurons. Nature 325:714-717.

- Sugita S, Goldsmith JR, Baxter DA, Byrne JH (1992) Involvement of protein kinase $C$ in serotonin-induced spike broadening and synaptic facilitation in sensorimotor connections of Aplysia. J Neurophysiol 68:643-651.

- Sugita S, Baxter DA, Byrne JH (1997) Modulation of a cAMP/protein kinase A cascade by protein kinase $\mathrm{C}$ in sensory neurons of Aplysia. J Neurosci 17:7237-7244.

- Suh PG, Park JI, Manzoli L, Cocco L, Peak JC, Katan M, Fukami K, Kataoka T, Yun S, Ryu SH (2008) Multiple roles of phosphoinositide-specific phospholipase C isozymes. BMB Rep 41:415-434.

- Susswein AJ, Schwarz M, Feldman E (1986) Learned changes of feeding behavior in $A p$ lysia in response to edible and inedible foods. J Neurosci 6:1513-1527.

- Sutton MA, Carew TJ (2000) Parallel molecular pathways mediate expression of distinct forms of intermediate-term facilitation at tail sensory-motor synapses in Aplysia. Neuron 26:219-231.

-Sutton MA, Masters SE, Bagnall MW, Carew TJ (2001) Molecular mechanisms underlying a unique intermediate phase of memory in $A p$ lysia. Neuron 31:143-154.

-Sutton MA, Bagnall MW, Sharma SK, Shobe J, Carew TJ (2004) Intermediate-term memory for site-specific sensitization in Aplysia is maintained by persistent activation of protein kinase C. J Neurosci 24:3600-3609.

- Tang WJ, Gilman AG (1991) Type-specific regulation of adenylyl cyclase by $\mathrm{G}$ protein beta gamma subunits. Science 254:1500-1503.

Tang WJ, Krupinski J, Gilman AG (1991) Expression and characterization of calmodulin-activated (type I) adenylylcyclase. J Biol Chem 266:8595-8603.
Taussig R, Tang WJ, Hepler JR, Gilman AG (1994) Distinct patterns of bidirectional regulation of mammalian adenylyl cyclases. J Biol Chem 269:6093-6100.

Tesmer JJ, Sunahara RK, Gilman AG, Sprang SR (1997) Crystal structure of the catalytic domains of adenylyl cyclase in a complex with Gsalpha.GTPgammas. Science 278:19071916.

Udo H, Jin I, Kim JH, Li HL, Youn T, Hawkins RD, Kandel ER, Bailey CH (2005) Serotonininduced regulation of the actin network for learning-related synaptic growth requires Cdc42, N-WASP, and PAK in Aplysia sensory neurons. Neuron 45:887-901.

Villareal G, Li Q, Cai D, Fink AE, Lim T, Bougie JK, Sossin WS, Glanzman DL (2009) Role of protein kinase $\mathrm{C}$ in the induction and maintenance of serotonin-dependent enhancement of the glutamate response in isolated siphon motor neurons of Aplysia californica. J Neurosci 29:5100-5107.

Walters ET, Byrne JH (1983) Associative conditioning of single sensory neurons suggests a cellular mechanism for learning. Science 219:405-408.

-Wayman GA, Impey S, Wu Z, Kindsvogel W, Prichard L, Storm DR (1994) Synergistic activation of the type I adenylyl cyclase by $\mathrm{Ca} 2+$ and Gs-coupled receptors in vivo. J Biol Chem 269:25400-25405.

Wei J, Wayman G, Storm DR (1996) Phosphorylation and inhibition of type III adenylyl cyclase by calmodulin-dependent protein kinase II in vivo. J Biol Chem 271:2423124235.
-Wei J, Zhao AZ, Chan GC, Baker LP, Impey S, Beavo JA, Storm DR (1998) Phosphorylation and inhibition of olfactory adenylyl cyclase by CaM kinase II in neurons: a mechanism for attenuation of olfactory signals. Neuron 21:495-504.

-Weiss KR, Mandelbaum DE, Schonberg M, Kupfermann I (1979) Modulation of buccal muscle contractility by serotonergic metacerebral cells in Aplysia: evidence for a role of cyclic adenosine monophosphate. J Neurophysiol 42:791-803.

Wing MR, Houston D, Kelley GG, Der CJ, Siderovski DP, Harden TK (2001) Activation of phospholipase C-epsilon by heterotrimeric G protein beta/gamma-subunits. J Biol Chem 276:48257-48261.

-Wing MR, Snyder JT, Sondek J, Harden TK (2003) Direct activation of phospholipase Cepsilon by rho. J Biol Chem 278:4125341258.

-Wong ST, Athos J, Figueroa XA, Pineda VV, Schaefer ML, Chavkin CC, Muglia LJ, Storm DR (1999) Calcium-stimulated adenylyl cyclase activity is critical for hippocampus-dependent long-term memory and late phase LTP. Neuron 23:787-798.

Wu Z, Wong ST, Storms DR (1993) Modification of the calcium and calmodulin sensitivity of the type I adenylyl cyclase by mutagenesis of its calmodulin binding domain. J Biol Chem 268:23766-23768.

Zhang Y, Helm JS, Senatore A, Spafford JD, Kaczmarek LK, Jonas EA (2008) PKC-induced intracellular trafficking of $\mathrm{Ca}(\mathrm{V}) 2$ precedes its rapid recruitment to the plasma membrane. J Neurosci 28:2601-2612.

-Zhao Y, Leal K, Abi-Farah C, Martin KC, Sossin WS, Klein M (2006) Isoform specificity of PKC translocation in living Aplysia sensory neurons and a role for $\mathrm{Ca} 2+$-dependent $\mathrm{PKC}$ Apl I in the induction of intermediate-term facilitation. J Neurosci 26:8847-8856. 